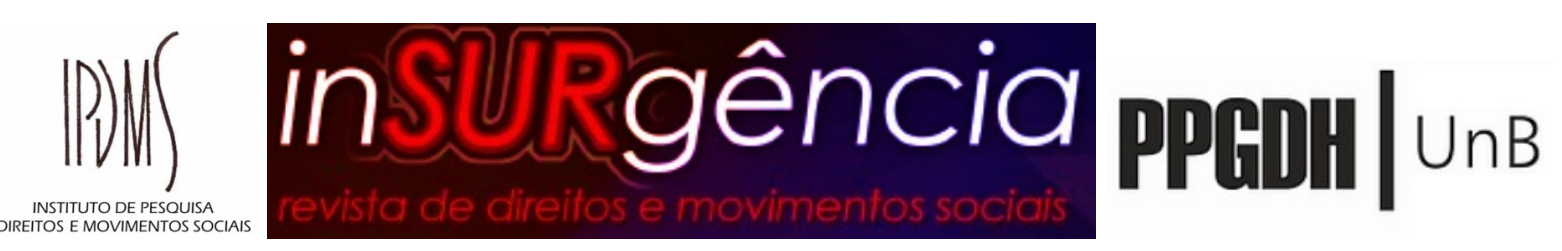

\title{
MOLDANDO O DIREITO À NORMA: O CONTO DE PONTAL E O PORTO E APROPRIAÇÃO PRIVADA DE TERRAS COMUNS
}

\author{
SHAPING THE LAW INTO THE RULE: THE TALE OF PONTAL AND THE PORT: \\ PRIVATE APPROPRIATION OF COMMON LANDS
}

Isabella Madruga da Cunha ${ }^{1}$

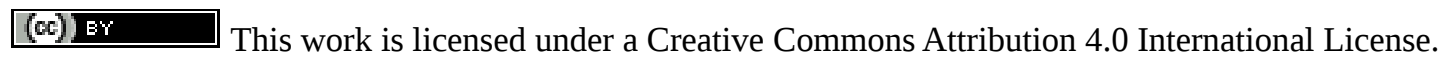

Resumo: Este artigo conta a história da apropriação privada de terras devolutas no litoral do Paraná. A história da relação entre essa apropriação e a criação de um município, e da criação desse município com o projeto de construção de um porto privado. Esta história é uma história do direito, mais especificamente da evolução jurídica da regulamentação da terra. Ao mesmo tempo é uma história de ilegalidades perpetradas ao passo e através do direito. Por meio de pesquisa documental este artigo utiliza o conceito de comuns para pensar a relação entre terras devolutas e a diversidade territorial brasileira.

Palavras-chave: Apropriação de terras; Terras devolutas; Megaempreendimentos; Ordenamento territorial; Comuns.

\begin{abstract}
This essay tells the history of private appropriation of public lands in the Cost of Paraná. The history of the relation between this appropriation and the creation of a municipality, and of the creation of this municipality and the project of building a private port. This history is a Law History, more specifically of the juridical evolution of land regulation. At the same time it is a history of illegalities perpetrated besides and through the Law. Through documental research, this article utilizes the concept of commons to think the relation between public lands and Brazilian territorial diversity.
\end{abstract}

1 Mestra em Meio Ambiente e Desenvolvimento pela UFPR, 2018. Bacharela em Direito também pela UFPR. Integra o Núcleo de Pesquisa e Extensão em Direito Socioambiental - EKOA, vinculado ao PPGD UFPR. Associada ao Instituto de Pesquisa em Direitos e Movimentos Sociais - IPDMS. Militante da RENAP-PR. É assessora jurídica do CAOP do Meio Ambiente, Habitação e Urbanismo do Ministério Público do Paraná. 


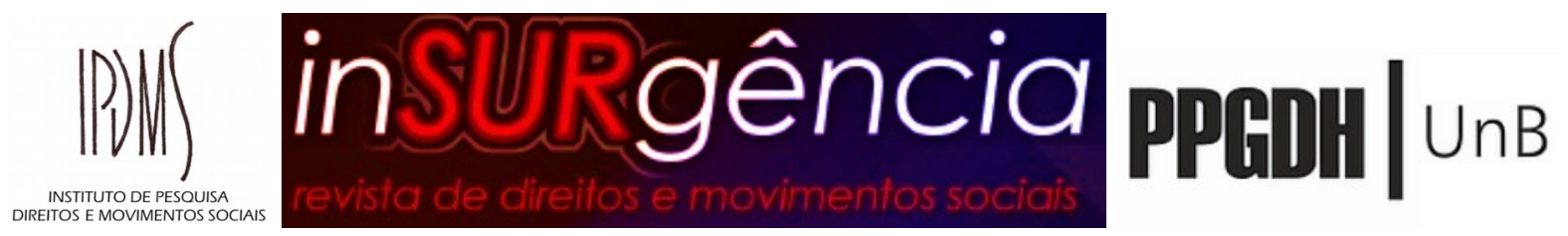

Key-words: Land appropriation; Public land; Mega-enterprises; Land use planning; Commons.

\section{Introdução}

Este artigo é fruto de pesquisa documental realizada a nível de mestrado que resultou na dissertação Cidade, lei e desenvolvimento: Pontal do Paraná uma estrada para o futuro?, apoiada por bolsa de pesquisa da Coordenação de Aperfeiçoamento de Pessoal do Ensino Superior - CAPES. A motivação da investigação foi compreender a relação entre a alteração de normas de ordenamento territorial a nível estadual - edição do Zoneamento Ecológico Econômico do Litoral do Paraná, revogação e edição de decretos estaduais - e municipal aprovação do novo Plano Diretor - e o projeto de implementação de um empreendimento privado em terras cuja legitimidade da titularidade é objeto de conflito, sendo parte delas território de comunidades tradicionais.

O recorte da pesquisa que apresentaremos neste artigo, enfoca exatamente o conflito sobre a titularidade das terras referidas, refazendo o percurso, através da análise documental, da transferência de cerca de 4 mil hectares de terras públicas devolutas para domínio privado. Partindo deste caso, que frise-se não é um caso de exceção na história fundiária brasileira, a proposta do artigo é denunciar a colonização do direito pelos interesses de mercado.

Nesta perspectiva o conceito de comum e sua genealogia proposta por Dardot e Laval na obra Comum: ensaios sobre a revolução no século XXI (2017) aparece como uma chave de leitura capaz de problematizar o papel do Estado no estabelecimento do público, demonstrando que a propriedade pública é muitas vezes de agência privada. Neste sentido, o artigo propõe uma discussão sobre a noção brasileira de terras devolutas e a ocupação destas terras por povos e comunidades tradicionais que estabelecem relações diversas com o espaço, produzindo o que Paul Little (2002) chama de “diversidade territorial brasileira”. Será que estas formas de relação com a terra e com o espaço próprias da realidade brasileira podem ser chamadas comuns? Qual a contribuição do conceito de comum para a luta pelos direitos territoriais, demarcação de terras indígenas, quilombolas e reconhecimento das posses de comunidades tradicionais? Sem se pretender a oferecer uma resposta final a estas questões, o artigo utiliza de um caso concreto para convidar a reflexões quanto ao papel do direito no aprofundamento das desigualdades fundiárias do país. 


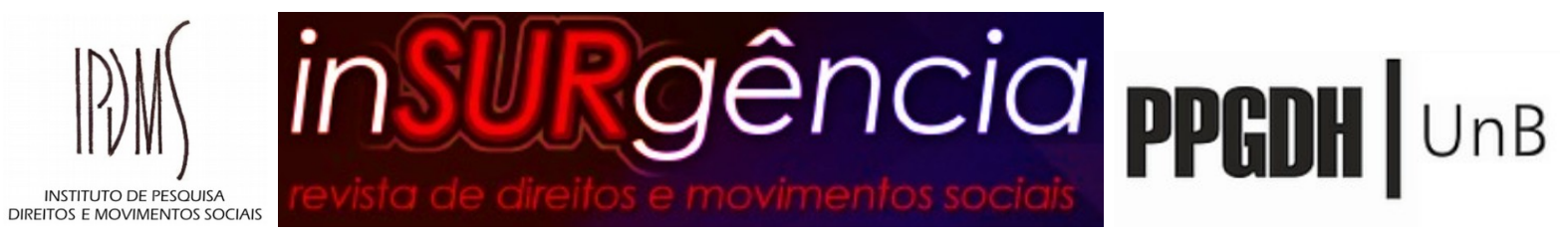

\section{O Conto}

A ideia de apresentar este artigo resultado de pesquisa acadêmica para realização de dissertação de mestrado com o título de “conto”, uma forma de texto literário inventivo que não parece combinar com um artigo científico, partiu da percepção de que a narrativa construída a partir da análise cuidadosa de documentos oficiais sobre o processo de transferência gratuita de terras públicas em Pontal do Paraná para o domínio de uma empresa privada depende de uma ficção jurídica e política para se perpetrar. Se por um lado, como se vai demonstrar no texto que se segue, as ilegalidades que envolvem o caso são evidentes, por outro, a segurança jurídica garantida pela existência de um papel, um título de propriedade, é tão perene que argumenta-se por sua legitimidade, desimportando os meios pelos quais foi obtido.

A figura do conto surge com o objetivo de evidenciar a ficção jurídica operada pela ordem proprietária, mesmo diante de um ordenamento jurídico edificado em torno da Constituição de 1988, que colocou no seu núcleo os direitos humanos fundamentais, estabelecendo o ônus da função social ao direito de propriedade, além de garantir o direito à terra.

Primeiro, necessário ambientar esta história. Pontal do Paraná é um dos sete municípios que compõem o litoral do Estado do Paraná. Costumava ser caracterizado como de “vocação econômica praiano-turística” (PIERRI, 2003), pois a urbanização do município esteve bastante relacionada com a ocupação com fins de turismo balneário, especialmente a partir dos anos 1950, quando ainda era parte do Município de Paranaguá até se tornar município independente em 1995. Entretanto, localizando-se na ponta da Baía de Paranaguá, situa-se numa região de ocupação humana bastante antiga, de cerca de 6000 anos, conforme demonstram os registros arqueológicos (SILVA, 1993).

Se numa das pontas da Baía de Paranaguá, onde hoje é o município de Paranaguá, desenvolveu-se um núcleo urbano com atividades portuárias, na outra, que equivale ao território de Pontal prevaleceu a ocupação dos pescadores-agricultores. Somente no final da década de 1920 que os territórios do litoral do Paraná em geral, e em especial a região de Pontal do Paraná, Ilha do Mel, Guaratuba, Matinhos e Caiobá, passaram a ser apropriados, pouco a pouco, para servirem ao turismo balneário (SAMPAIO, 2006). A partir da década de 


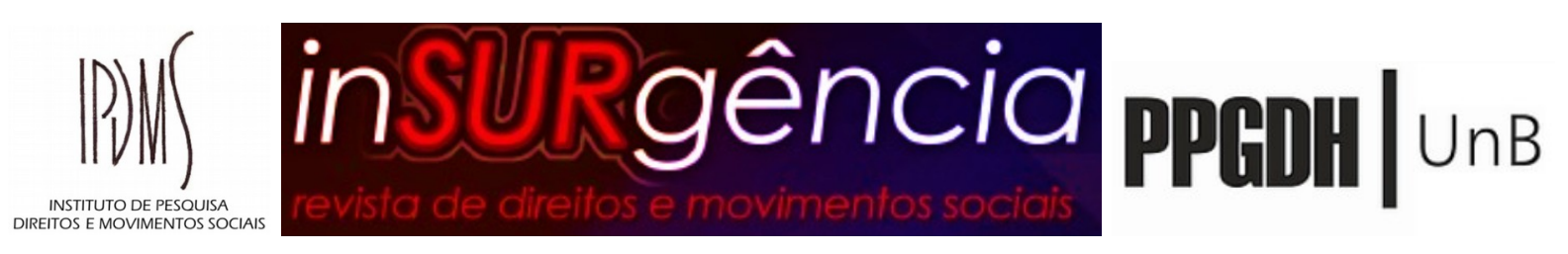

1950 esse movimento foi acelerado e os loteamentos balneários foram se multiplicando na região de Pontal e em outras regiões do litoral paranaense e brasileiro, vinculado a conjuntura econômica favorável das décadas de 1940 a 1980, quando a despeito da concentração de riqueza no país ter aumentado, proporcionou-se um aumento na capacidade de consumo da população em geral, conforme analisa Ermínia Maricato (2013a).

Esse momento de otimismo econômico propiciou que as classes médias investissem nas atividades de lazer, tal qual turismo, o que acabou por acelerar a apropriação balneária do litoral, não apenas paranaense. Por outro lado, as políticas públicas de habitação e crédito da época voltavam-se apenas para as classes médias, excluindo uma enorme parcela da população brasileira. O mercado fundiário se estabeleceu caracterizado pela intensa especulação, impedindo o acesso das classes baixas a terra regularizada. Este fenômeno que explica a multiplicação de favelas e vilas, onde as condições de vida da população urbana são bastante precárias, tendo-se cunhado para esse processo o termo "urbanização da pobreza” (MARICATO, 2014).

O marco espaço-temporal que alavancou a urbanização de Pontal do Paraná foi o lançamento do loteamento “Cidade Balneária Pontal do Sul”, em 1951, “o maior empreendimento balneário do litoral paranaense até o presente” (SAMPAIO, 2006, p. 175). Não há como falar na urbanização de Pontal do Paraná, sem mencionar a Empresa Balneária Pontal do Sul, responsável pelo empreendimento. Esse processo de urbanização antecedeu mesmo a fundação da cidade, ou de um núcleo urbano. É precisamente a origem do empreendimento Cidade Balneária, que a protagonista deste conto.

A despeito de serem ocupadas pelas comunidades agropesqueiras, quase toda extensão de terras do que hoje é o município de Pontal do Paraná pertenciam ao Estado do Paraná, até a década de 1950. Eram terras devolutas, que não são terras desocupadas, mas sim terras não oficialmente adquiridas, conforme se estabeleceu desde a promulgação da Lei de Terras de 1850 (MARÉS, 2003). Foi o artigo 64, da Constituição da República de 1891, que tornou as terras devolutas propriedade dos estados federados. Desde então, o Estado do Paraná passou a ser agente fundamental no processo de apropriação privada das terras em seu domínio, sendo que a Constituição Estadual de 1892 “expressava a responsabilidade do Estado no que tange à política de terras” (PRIORI, 2012, p. 134), regulamentada pela Lei Estadual 68/1892 que seguindo a lei federal, determinava que as terras do Estado do Paraná só 


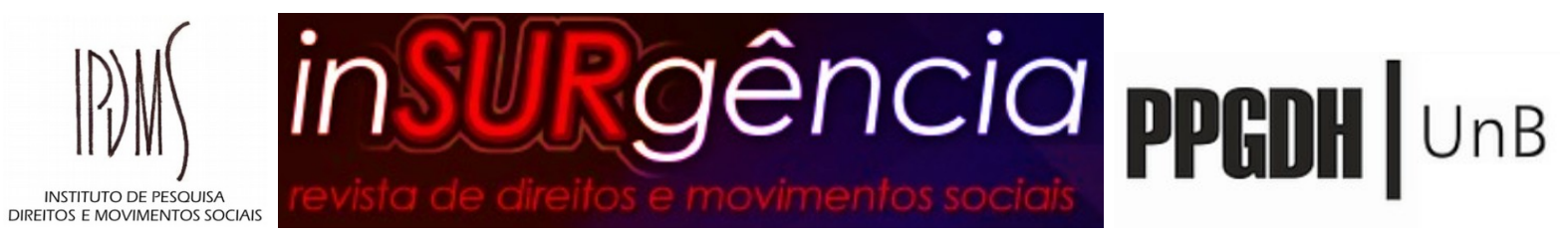

poderiam ser adquiridas por meio de compra ou aforamento (contrato que não implica na cessão de direito de propriedade pleno da terra).

Tudo começou em 1948 quando, através de um ofício, Prefeitura de Paranaguá solicitou ao Estado do Paraná a cessão gratuita de aproximadamente 3000 hectares de terra na localidade de Pontal do Sul. Em 1949, durante o governo de Moises Lupion, a Assembleia Legislativa do Estado do Paraná por meio da Lei Estadual 249/1949, autorizou o poder executivo do Estado a fazer uma "cessão gratuita”, conforme o artigo $1^{\circ}$ da lei, de terras devolutas situadas em Pontal do Sul a serem demarcadas. Conforme o texto completo da Lei Estadual 249/1949:

\begin{abstract}
Súmula: Autoriza o Poder Executivo a ceder ao município de Paranaguá, gratuitamente, terras devolutas em Pontal do Sul, no mesmo município. A Assembléia Legislativa do Estado do Paraná decretou e eu sanciono a seguinte lei: Art. $1^{\circ}$. Fica o Poder Executivo autorizado a ceder gratuitamente, ao Município de Paranaguá, uma área de terras devolutas, a ser demarcada, situada no Pontal do Sul, município de Paranaguá, delimitada: ao norte pela Baía de Paranaguá; a léste pelo Oceano Atlântico; ao sul pelo rio Olho d'Agua e a oeste por uma linha sêca de rumo Norte-Sul verdadeira que parte do Rio Maciel até encontrar o Rio Olho d'Agua, com a área de $\mathbf{3 . 0 0 0}$ (três mil) hectares aproximadamente, correndo as despesas de demarcação por conta da Prefeitura de Paranaguá. Art. $2^{\circ}$. A área cedida deverá ser aproveitada para os seguintes fins: a) Incentivar a pesca; b) construção de uma estrada ligando Paranaguá ao Pontal do Sul; c) formação de lótes para granjas destinadas ao plantío de lavouras próprias do litoral; d) formação de pequeno balneário. Art. $3^{\circ}$. A presente cessão é feita sob a condição da Prefeitura de Paranaguá respeitar a posse dos atuais moradores naquela área e regularisar o domínio dos proprietários, se houver, nos têrmos da Lei Imperial $\mathrm{n}^{\circ} 601$, de 18 de setembro de 1850 , e do Regulamento $\mathrm{n}^{\circ} 1.318$, de 30 de janeiro de 1854, e Lei Estadual n ${ }^{\circ}$ 68, de 20 de dezembro de 1892, e seu regulamento. Art. $4^{\circ}$. Revogamse as disposições em contrário. PALÁCIO DO GOVÊRNO EM CURITIBA, em 12 de setembro de 1.949 (PARANÁ, Lei estadual 249/1949, grifos nossos).
\end{abstract}

No ano seguinte, a prefeitura de Paranaguá por meio da Lei Municipal nº 56/1950, estabeleceu o que chamou de “Contrato de Concessão” de uma área de 3000 hectares na localidade de Pontal do Sul, para Antonio B. Pereira, João Goiz Saião Filho e Luiz Ferraz de Mesquita ou a empresa que constituírem, sob a condição de fundarem o loteamento "Cidade Balneária Pontal do Sul”. Em dezembro de 1950, funda-se a “Empresa Balneária Pontal do Sul S/A” (doravante denominada "Empresa Balneária”), utilizando a área que havia sido doada àqueles particulares para a integralização de seu capital. Embora o contrato de concessão das terras entre prefeitura e Empresa Balneária tenha sido celebrado em 1950, a própria prefeitura só foi receber do Estado do Paraná o título em 1951.

O “Título de Domínio Pleno de Terras n 197” (certidão n 217/80) foi emitido pelo Estado do Paraná em janeiro de 1951, transferindo a propriedade das terras devolutas em Pontal para o município de Paranaguá. Este não menciona se tratar de “cessão gratuita”, termo 


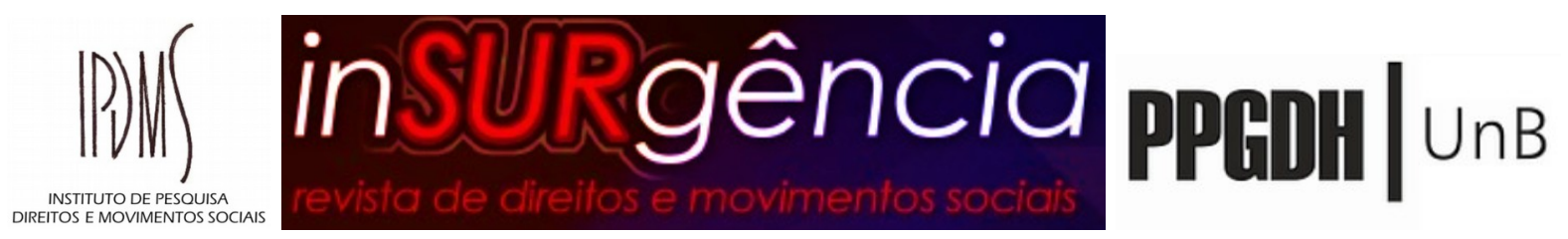

utilizado na Lei Estadual 249/1949, mas de “dação em pagamento”, um instrumento jurídico completamente diverso que pertence ao direito das obrigações que é ramo do direito privado. Além do mais, o título de propriedade emitido pelo Estado do Paraná aumentou consideravelmente a área a ser transferida, em relação ao determinado na Lei Estadual 249/1949 - de 3.000 hectares passaram a ser 4.303,32 hectares. Não há, em nenhum dos registros documentais acessados, menção do porquê dessa alteração. Entretanto, se tratou de ato do poder executivo do Estado que contrariou a lei estadual que o autorizou, a referida Lei Estadual 249/1949, que autorizava a cessão de exatamente 3000 hectares de terras.

No mesmo ano, a prefeitura de Paranaguá celebrou a transferência da integralidade das terras recebidas do estado para a Empresa Balneária. A Empresa Balneária contratou o projeto urbanístico da "Cidade Balneária Pontal do Sul” apenas em 541ha da área total que recebeu e assim inaugurou o maior loteamento de Pontal do Paraná e de todo o litoral do Estado.

Em síntese, o processo de transferência das terras devolutas do Estado do Paraná para a prefeitura de Paranaguá foi realizado por meio de dois documentos nos quais ganhou dois nomes e, portanto, foi relacionado a dois instrumentos jurídicos distintos: i) "cessão gratuita” na Lei Estadual 249/1949 e ii) “dação em pagamento” no Título de Domínio Pleno de Terras $n^{\circ} 197$ (certidão $n^{\circ}$ 217/80) emitido em 1951. O artigo $3^{\circ}$ da lei 249/1949 estabelece condições para a efetivação da transferência das terras, encargos ao município Paranaguá, não estabelecendo nenhum prazo para que estes sejam cumpridos.

No transcurso desses mais de 60 anos a prefeitura nunca cumpriu os encargos estabelecidos para a realização da cessão. Porquanto, o Título de Domínio Pleno das Terras, emitido pelo poder executivo do Estado do Paraná em janeiro de 1951, indicava se tratar de “dação em pagamento” aumentando em cerca de 40\% a área de terras cuja propriedade foi transferida para a prefeitura de Paranaguá, em relação do que estabelecia a Lei Estadual 249/1949, lei que autorizou este ato administrativo. É norma do direito administrativo que o ato administrativo deve estar em conformidade com a lei autorizadora e a desconformidade enseja em nulidade do ato.

A análise do processo de transferência da propriedade das terras devolutas em Pontal do Paraná, do Estado do Paraná para a prefeitura de Paranaguá, portanto, já contém ilegalidades que por si só indicariam a nulidade do ato de transferência de propriedade. Por sua vez, antes mesmo de o Estado emitir o título de propriedade destas terras para o 


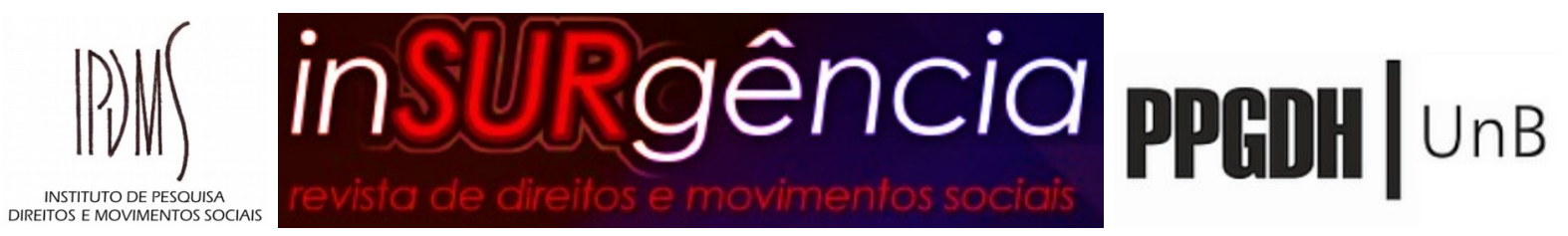

Município de Paranaguá, este já havia concedido-as para um ente privado. Esse processo tem como marco a Lei Municipal 56/1950 que concedeu a propriedade das terras à Empresa Balneária conforme contrato que é anexo à lei, que celebra e estabelece os termos da relação entre ente público municipal e empresa privada. Este ato jurídico é denominado "Contrato de concessão de terras e fundação da cidade balneária do Pontal do Sul”.

O contrato de concessão de terras anexo a Lei Municipal 56/1950, celebrado entre município de Paranaguá e Empresa Balneária, estabelecia a obrigação da empresa construir uma “Cidade Balneária”, em área determinada, cujo projeto deveria obedecer “aos mais modernos preceitos de colonização no gênero”. O contrato estabelecia uma série de outras obrigações de fazer à empresa, como por exemplo, a construção de uma pista de pouso e de uma estrada.

A Lei Municipal 56/1950 publicada em janeiro ainda determinava a transferência de exatamente 3000 hectares de terra, como previa a Lei Estadual. Entretanto, no mesmo ano, em novembro de 1950, a Lei Municipal 53 de Paranaguá foi alterada em seu art. $1^{\circ}$ pela Lei Municipal 73/1950, que retirou do texto legal menção ao tamanho da área. Muito provavelmente, para se adequar ao título de propriedade que logo em seguida seria emitido pelo poder executivo do Estado do Paraná, em 1951. Portanto, cabe concluir que o Estado do Paraná tinha ciência de que as terras em questão se destinavam à iniciativa privada. Ainda em 1950, no mês de dezembro, Antonio B. Pereira, João de Goiz Saião Filho e Luiz Ferraz de Mesquita fundaram a "Empresa Balneária Pontal do Sul S/A”, utilizando a área que havia sido prometida pela prefeitura de Paranaguá por meio da Lei Municipal 56/1950 para integralização do capital da empresa, conforme autorizado pelo contrato anexo a referida lei celebrado entre prefeitura e empreendedores.

Acompanhando a narrativa documental fica difícil compreender qual espécie de negócio jurídico se tratou esta transferência de terras públicas para a iniciativa privada. Por um lado, a Lei Municipal 56/1950, utilizou o termo “ceder e transferir” para se referir ao ato jurídico celebrado com a Empresa Balneária, tal qual o contrato celebrado entre prefeitura e Empresa Balneária é intitulado “contrato de concessão de terras”. O que poderia fazer interpretar que era o caso de concessão pública em que se transfere apenas o direito de uso e exploração do bem público ao ente privado e por prazo determinado. Tendo o Estado do Paraná emitido o Título de Domínio Pleno de Terras nº 197 (certidão nº 217/80), porém, no mesmo dia seguinte, em $1^{\circ}$ de fevereiro de 1951, a prefeitura transferiu a propriedade plena 


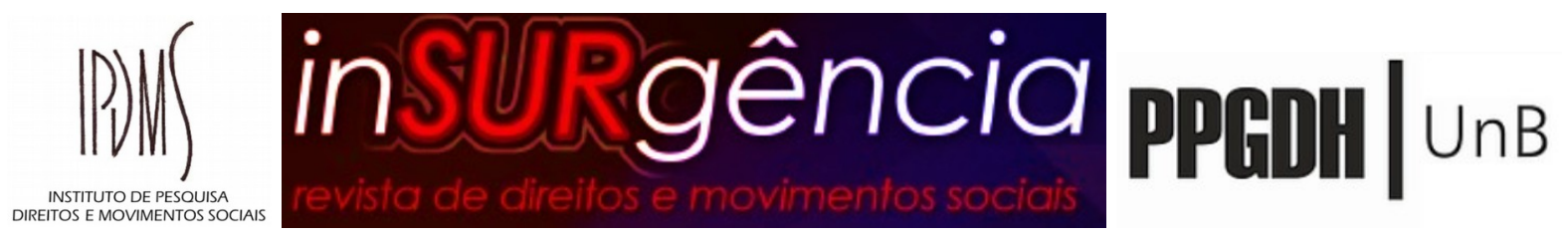

das terras para a recém fundada Empresa Balneária, conforme Certidão de Transcrição no 6624 lavrada no $2^{\circ}$ Tabelião José Luiz Pinto Rebello de Paranaguá. Com a transferência do direito de propriedade pleno das terras para a Empresa Balneária, descaracterizou-se a concessão, tendo ocorrido de fato a alienação de um bem público a ente privado.

Cabe ressaltar que a lei que vigente na época não autorizava esse tipo de transação entre entes públicos e privados. Conforme a Lei Estadual 64/1948, Lei Orgânica dos Municípios do Paraná:

Art. 51 Compete ao prefeito: (...) XIII. Vender bens municipais, contratar serviços, obras e funcionamentos, após a autorização da Câmara e mediante concorrência ou hasta pública; (PARANÁ, Lei 64/1948, artigo 51, XIII).

A lei explicitamente permitia apenas a venda de bens públicos e ainda determinava que era necessária autorização da Câmara municipal mediante prévia concorrência ou hasta pública para tanto, processos que não foram realizados no caso em questão. A desconformidade das Leis Municipais 56 e 73/1950 com a Lei Orgânica dos Municípios do Paraná de 1948, também confronta o princípio da legalidade, mais um vício deste processo capaz de gerar nulidade. E se mesmo diante disso, fosse considerado legal o contrato estabelecido entre administração municipal e empresa privada, a nulidade poderia ser argumentada pelo descumprimento contratual, uma vez que de todas as obrigações de fazer listadas a empresa somente loteou e colocou à venda 4557 terrenos, não tendo entregue as contrapartidas estabelecidas em acordo.

Toda essa engenharia jurídica não passou em branco ao longo dos anos. Primeiro, em 1960, 10 anos depois da celebração do "Contrato de concessão de terras e fundação da cidade balneária do Pontal do Sul” entre prefeitura de Paranaguá e Empresa Balneária, o município promulgou a Lei Municipal 385/1960, que mandava promover a rescisão do contrato com a Empresa Balneária de forma amigável ou por meio de ação judicial. Essa lei, no entanto, nunca foi implementada e o contrato seguiu vigente. No ano de 1965, o Município de Paranaguá aprovou uma emenda à Lei Municipal 53/1950 que versava sobre a reformulação do referido contrato de concessão de terras, demandando a empresa a construção de uma estrada ligando Guaraguaçu a Pontal do Sul em 120 dias, que instalasse energia elétrica no loteamento da "Cidade balneária Pontal do Sul”, e que regularizasse imediatamente a situação dos posseiros da área. Também não se levou a cabo a execução desta lei, sendo que essas posses nunca foram demarcadas. 


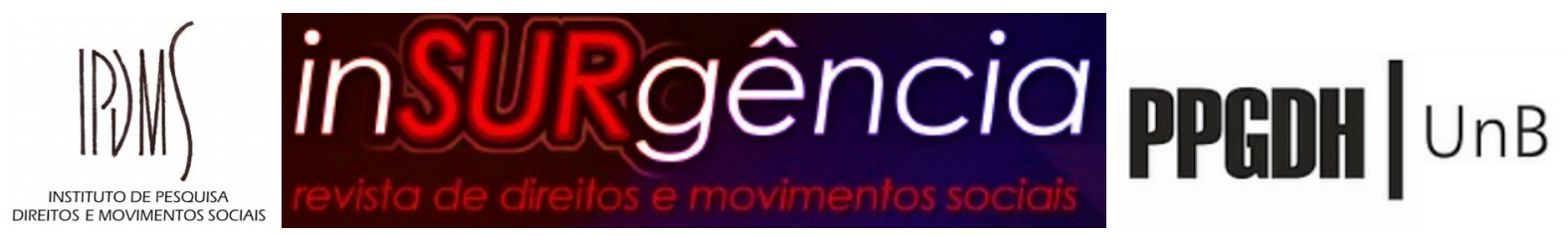

Mais recentemente, no ano de 2015, foi instaurada uma Comissão Parlamentar de Inquérito (CPI) na Assembléia Legislativa do Estado do Paraná (ALEP) para apurar a “Ocupação fundiária de Pontal do Sul” cujos trabalhos foram concluídos no mesmo ano. Grande parte dos documentos aqui analisados foram acessados através da disponibilização online dos arquivos da CPI, no endereço eletrônico da ALEP². Porém, mesmo diante dos indícios aqui apresentados, a CPI concluiu pela legalidade dos atos jurídicos praticados por Estado do Paraná, Prefeitura de Paranaguá e Empresa Balneária, tomando para isso como base doutrinária a “Teoria da recepção da lei anterior pela Constituição”, alegando que a simples decorrência do tempo ou de lei nova não revoga a anterior a não ser que explicitamente o determine. O relatório final da CPI, afirma

Diante do fato de estar sob análise desta CPI, atos jurídicos que foram recebidos com base em leis editadas antes do advento da atual Constituição, importante lembrar que referidas leis estão em vigência. (...) Diante do estudo, ora exposto, compreende-se que resta superada a discussão a respeito da validação dos atos realizados, com fulcro na legislação anterior à presente Constituição da República, sendo que a norma infraconstitucional foi recepcionada na nova ordem ${ }^{3}$.

O estudo referido, que apresenta a tese utilizada como fundamento da decisão do relatório da CPI é o texto de um blog sem indicação de autoria (civilize-se.blogspot.com.br). Trata-se de tese não majoritária na área jurídica e que tampouco aplicaria-se ao caso em questão, já que não haveria apenas incompatibilidade com a Constituição atual, mas também com as normas de direito vigentes à época da prática dos atos administrativos que acabaram por transferir patrimônio público para uma empresa privada.

\section{O Porto}

Como um município, Pontal do Paraná foi criado em 1995, por meio da Lei Estadual 1152/1995. Sendo originalmente uma área de praia com vilas de pescadores, ou comunidades agropesqueiras, a região que hoje é o município foi se tornando uma cidade balneária. Ao término da década de 1990, a orla já estava toda apropriada por 45 balneários regulares, somando-se a estes os oriundos de loteamentos ilegais. Um outro projeto, porém, permeou a emancipação de Pontal do Paraná como município. No mesmo ano de 1995 foi fundada a

2 Cf. http://www.assembleia.pr.leg.br/atividade_parlamentar/comissoes/cpi-ocupacao-fundiaria-de-pontal-doparana.

3 CPI Ocupação Fundiária de Pontal do Sul, Relatório Final, p.75-78, acesso em 05/10/2019, disponível em http://www.alep.pr.gov.br/atividade_parlamentar/comissoes/cpiocupacao-fundiaria-de-pontal-do-parana 


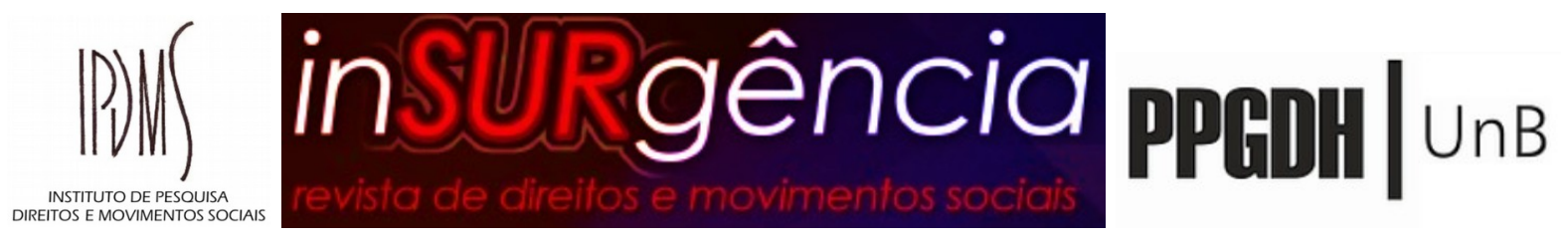

empresa “Porto Pontal Paraná Importação e Exportação LTDA” cujo capital está voltado para a construção do “Terminal Privado de Contêineres de Pontal do Paraná” (TCPP).

O local propício para a construção de um terminal portuário em Pontal do Paraná é exatamente em Pontal do Sul, em parte do território que a Empresa Balneária recebeu do poder público na década de 50 do século passado. A região é reconhecida por sua vocação industrial-portuária, tendo já na década de 1970 recebido indústrias do ramo da construção de plataformas petrolíferas. O projeto de um porto em Pontal do Paraná sempre esteve vinculado a iniciativa privada, ainda que a atividade portuária tenha deixado de ser monopólio estatal somente dois anos antes ${ }^{4}$ da criação da empresa portuária local.

Em 2006, o Grupo Empresarial JCR, adquiriu a empresa "Porto Pontal do Sul Importação e Exportação S/A”, o mesmo grupo empresarial controla a Empresa Balneária. O “Porto Pontal” figura como protagonista na agenda da prefeitura municipal e da ACIAPAR, a associação comercial do município, a perspectiva é de deixar de ser um município de vocação “praiano-turística” para se tornar uma cidade portuária, atraindo investimentos e indústrias do ramo petrolífero novamente. Em 2014 o projeto do porto de Pontal do Paraná foi autorizado pela Agência Nacional de Transportes Aquaviários (ANTAQ) e no ano seguinte, 2015, teve a licença ambiental de instalação concedida pelo IBAMA.

Tanto governo estadual quanto municipal tem manifestado grande interesse e apoio ao projeto do Porto Pontal Paraná. Isto é evidenciado pelas manifestações na mídia, pela iniciativa de adequar o ordenamento territorial da região ao empreendimento, bem como pelo investimento público na viabilização do projeto, já que o Estado do Paraná assumiu a obra de construção de uma estrada que servirá para o escoamento do porto e que foi estabelecida pelo órgão licenciador como condição para a liberação da construção do empreendimento portuário. O empenho destes atores em efetivar o projeto de construção do porto privado invisibiliza os impactos que ele trará para as comunidades locais. Por outro lado, o discurso que alia a construção do porto a ideia de desenvolvimento e crescimento econômico torna os críticos ao projeto inimigos da própria cidade.

O local que receberá o porto era habitado por uma comunidade tradicional pesqueira, a comunidade da "Ponta do Poço", que durante o processo de licenciamento ambiental do terminal portuário foi realocada às custas da empresa, mas não sem resistência a essa solução. Outra comunidade tradicional que se sente ameaçada pela construção do porto é a do Maciel,

4 Refere-se a aprovação da Lei 8630/1993, conhecida como “Lei de Modernização dos Portos”. 


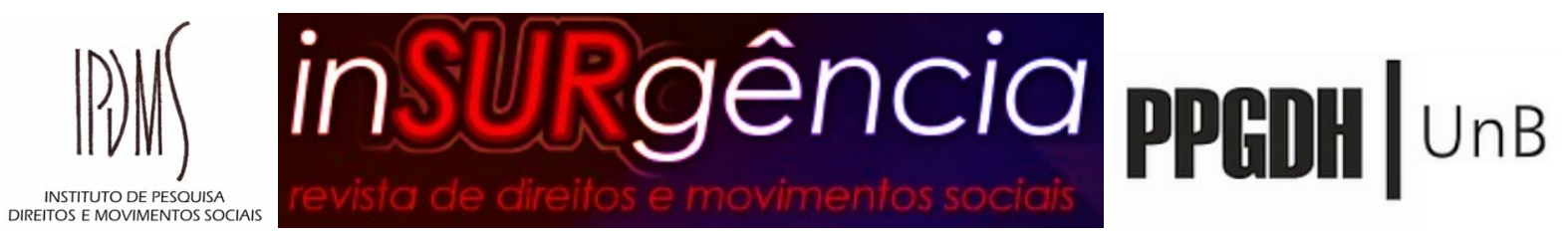

cuja área foi demarcada no zoneamento do novo Plano Diretor do Município, elaborado com intuito de adequar o ordenamento territorial municipal aos novos projetos de desenvolvimento para a cidade, como de “expansão portuária”.

Essas comunidades antes da concretização do projeto do porto, já sofriam da situação de insegurança da posse dos territórios em que vivem. Uma vez que as áreas em que moram são propriedade da Empresa Balneária, que nunca demarcou e reconheceu seus direitos ao território, conforme mandava a própria lei que lhe transferiu o domínio (Lei Estadual $\mathrm{n}^{\circ}$ 249/1949). Além dessas comunidades diretamente afetadas pela instalação do empreendimento, todas as comunidades tradicionais pesqueiras do município tendem a ser impactadas em maior ou menor grau pelo que a atividade portuária deverá interferir na qualidade e quantidade dos recursos pesqueiros.

A região do litoral paranaense abriga, junto ao litoral sul de São Paulo, um dos remanescentes de floresta atlântica do país, nesse sentido cabe também ressaltar a importância ecológica local. Como resultado da atuação ambientalista na década de 1980, várias unidades de conservação federais e estaduais foram criadas no litoral do Paraná e o ordenamento territorial da região estabelecia usos bastante restritivos, fundado no objetivo de conservação. Este ordenamento territorial foi bastante alterado para atender ao projeto do porto privado de Pontal do Paraná e de alguns outros projetos de desenvolvimento regionais.

Percebe-se uma tendência à flexibilização da normativa ambiental com o fim de receber investimentos e empreendimentos de porte, enquanto por outro lado, há um controle rígido dos órgãos ambientais sobre os pescadores e agricultores locais quanto às práticas extrativistas destes. Fato é que há uma incidência política importante de organizações ambientalistas na região, atualmente reunidas no "Observatório de Conservação Costeira do Paraná - OC2” e estas têm se constituído uma das vozes mais eloquentes contra o projeto de implementação do porto privado. Aliadas, neste contexto, às comunidades locais, as organizações ambientalistas têm movimentado a imprensa com intuito de sensibilizar a população quanto aos impactos negativos que o empreendimento portuário trará para a cidade, afetando também o turismo balneário.

Até 2017, vigiam dois dispositivos de ordenamento territorial que obstaculizavam a implementação dos empreendimentos de cunho industrial e portuário em Pontal do Paraná, trata-se dos Decretos Estaduais 2722/1984 e 5040/1989. Estes estabeleciam a região visada para construção do porto como área especialmente protegida, o termo utilizado na legislação 


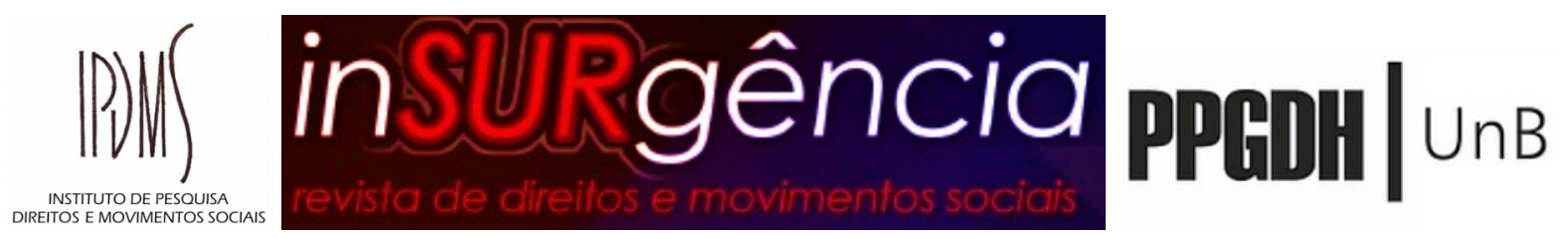

era de “unidades ambientais naturais”, proibindo o uso industrial e portuário daquele território. Este impedimento normativo foi afastado por dois importantes instrumentos de ordenamento territorial, o Zoneamento Ecológico-Econômico (ZEE) do Litoral Paranaense, Decreto Estadual 4996/2016, e o novo Plano Diretor de Pontal do Paraná, Decreto Estadual $5980 / 2017$.

O ZEE do Litoral do Paraná, Decreto Estadual 4996/2016, é atualmente o principal instrumento de ordenamento territorial da região do litoral. Enquanto instrumento regional que pretende orientar as ações estatais e do setor privado, definindo os usos e vocações das porções do território o ZEE acaba por adquirir um contorno de instrumento que se pode chamar de tradução de projetos de desenvolvimento, "sua expressão espacializada” (ACSELRAD, 2000, p. 9). É o que se percebe da análise do ZEE do litoral do Paraná.

O ZEE do litoral, por meio do decreto estadual 4996/2016, cria seis zonas em que divide e organiza ecológica e economicamente o litoral do Paraná: zona protegida por legislação ambiental específica (ZPL), zona urbana (ZU), zona de proteção dos mananciais (ZPM), zona de desenvolvimento das terras ocupadas (ZDTO), zona de expansão para unidades de conservação de proteção integral (ZEPI), zona de desenvolvimento diferenciado (ZDD). Quase todo território de Pontal do Paraná é estabelecido como zonas urbanas (ZU) e zonas de desenvolvimento diferenciado (ZDD), sendo que quase toda região de Pontal do Sul, incluindo a Ponta do Poço e o território da comunidade tradicional pesqueira do Maciel, é definida como ZDD. A diferença entre o zoneamento da “zona urbana” e da "zona de desenvolvimento diferenciado” é que nesta última há tendência para expansão portuária e industrial.

O Decreto Estadual 5980/2017, por sua vez, é o decreto de instituição do Plano Diretor de Pontal do Paraná, aprovando o regulamento que define as leis de zoneamento, uso e ocupação do solo do município ${ }^{5}$. Houve preocupação na promulgação deste decreto com o possível conflito de normas, de modo que há um dispositivo no Decreto, o artigo $4^{\circ}$, que

5 Necessário fazer uma explicação de porque normativa de competência municipal é referida como decreto estadual, neste caso o plano diretor. O Decreto Estadual 4605/1984, que instituiu e definiu as competências do Conselho de Desenvolvimento Territorial do Litoral Paranaense (COLIT), determina que todos os planos diretores dos municípios do litoral devem passar pela aprovação do conselho para então entrar em vigência, depois da aprovação do conselho a proposta de plano diretor retorna a câmara municipal que vota novamente sua aprovação ou rejeição. Essa possibilidade de o conselho de âmbito regional interferir em legislação de ordenamento territorial que é de competência municipal, como é o caso dos planos diretores conforme a Lei Federal 10257/2001, se extrai de uma combinação entre o art. 13 da Lei Federal 6766/1979, que estabelece competência especial aos estados para decidir sobre loteamento e desmembramento do solo em áreas demarcadas como áreas de especial interesse turístico (AEIT), com a Lei Estadual 12243/1998 que estabelece a região correspondente aos municípios do litoral como AEIT. 


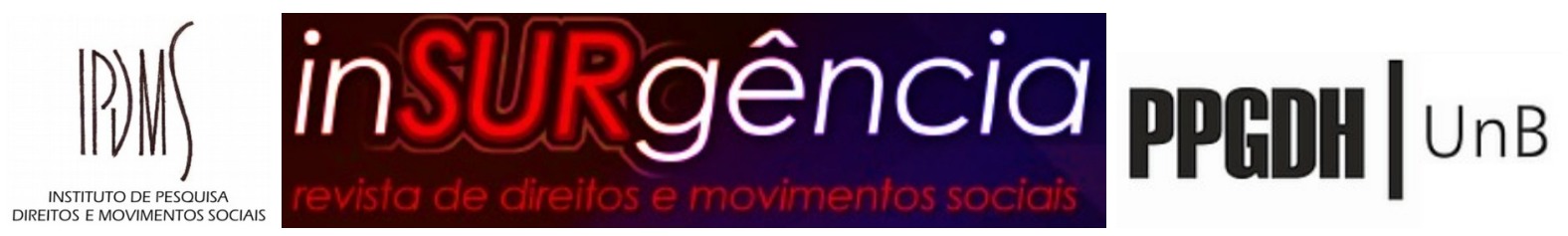

declara a revogação expressa dos Decretos Estaduais 2722/1984 e 5040/1989 no que se refere aos territórios de Pontal do Paraná. A área reservada ao futuro porto privado, que no ZEE é zona de desenvolvimento diferenciado (ZDD), no Plano Diretor é zona especial portuária (ZEP), inclusive o território da comunidade tradicional pesqueira do Maciel. Não só a comunidade do Maciel é ignorada no Plano Diretor, nenhuma comunidade tradicional pesqueira é mencionada enquanto tal. O que se tem é o reconhecimento da existência de algumas comunidades em situação de insegurança da posse, com a demarcação de zonas especiais de interesse social (ZEIS), cuja criação facilita o processo de regularização fundiária.

Como o objetivo deste texto não é fazer uma análise minuciosa destas normativas ${ }^{6}$, traz-se seus aspectos gerais apenas para demonstrar que houve uma atuação política para adequar o ordenamento jurídico, no caso o ordenamento territorial, a um projeto de empreendimento privado, que os governos estadual e municipal classificam como de interesse público. Porém, aos quais cabe questionar interesse de quem? Quais atores este projeto beneficiará? Embora haja uma promessa de empregos, sabe-se que trata-se de um empreendimento altamente mecanizado que demanda pouca e especializada mão-de-obra. Os rendimentos da atividade portuária serão lucros para a empresa que controlará o porto, proporcionarão o aumento do PIB (Produto Interno Bruto) do município, mas não significarão necessariamente distribuição de renda. Sendo assim, o porto de pontal parece ser mais um produto do que Olívia Arantes chamou de “a fabricação de consensos em torno do crescimento a qualquer preço” (ARANTES, 2013, p. 27), que colou a ideia de crescimento econômico com o aumento exponencial da oferta de empregos.

\section{Terras devolutas, diversidade territorial e os Comuns}

O caso de Pontal do Paraná se observado desde uma perspectiva histórica, relacionado às práticas perpetuadas pelo governo paranaense especialmente na primeira metade do século XX, pode ser situado no contexto amplo das transferências de terras públicas para entes privados, perpetuando a lógica de apadrinhamentos políticos (SERRA, 2005). Esta tem raízes no próprio traçado da política fundiária brasileira, que possibilitou o

6 Para análise pormenorizada conferir: CUNHA, Isabella Madruga da. Cidade, Lei e Desenvolvimento: Pontal do Paraná, uma estrada para o futuro? Dissertação (Mestrado em Meio Ambiente e Desenvolvimento.Curitiba: UFPR, 2018. Disponível em: <https://acervodigital.ufpr.br/handle/1884/58910>, último acesso em 27 de julho de 2020. 


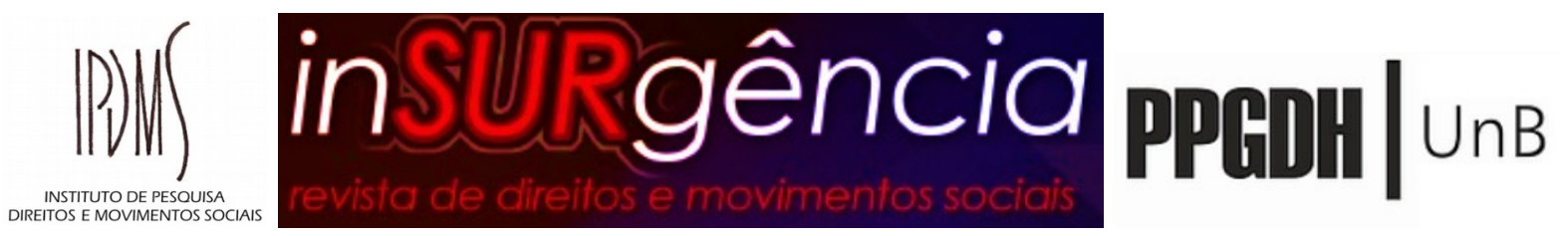

fortalecimento das oligarquias estaduais e a intensificação do processo de formação de latifúndios através da aplicabilidade restrita da Lei de Terras de 1850 e da transferência da propriedade das terras devolutas para os Estados federados, desde a outorga da Constituição de 1891. Analisar historicamente a política fundiária é, portanto, também analisar a perversão do Estado e da máquina pública pelos interesses do que se nominou oligarquia local. Conforme Ermínia Maricato:

Desde 1854, quando é regulamentada a lei de terras de 1850, até praticamente os nossos dias, as terras devolutas têm sido privatizadas, tirando proveito de uma situação de fragilidade da demarcação da propriedade da terra no Brasil durante mais de quatro séculos, apesar das medidas que buscaram proteger o patrimônio público (MARICATO, 2013b, p. 149).

O caso da apropriação privada de terras em Pontal do Paraná figura como um exemplo contundente da afirmação da autora. Desde 1951 quando as terras foram transferidas para domínio privado mesmo com as sucessivas alterações no ordenamento jurídico com vistas em proteger o patrimônio público, foram se perpetuando e consolidando no tempo uma série de ilegalidades.

Isto sem mencionar que não se trata apenas aqui de proteção da propriedade pública, mas também da desconsideração das pessoas que tinham e têm a posse da terra, posse essa reconhecida pelo próprio Estado do Paraná desde a edição da Lei Estadual 249/1949. Deste modo, o que se observa é a imposição da lei de mercado sobre a norma jurídica, num mercado restrito e não concorrencial, como é o de terras urbanas no Brasil. Ou seja, um mercado que funciona sobretudo através da renovação de privilégios. "No lugar dos direitos individuais persiste a clássica relação de favor que na esfera da política implica nas trocas clientelistas” (MARICATO, 2013a, p. 42).

O conceito de terras devolutas, categoria que podemos encaixar as terras de Pontal do Paraná protagonistas deste conto antes da apropriação privada, é uma criação própria do direito brasileiro. Em seu sentido original, do período colonial, tratava-se da obrigação de devolver as terras doadas pela coroa através do instituto das sesmarias caso estas não fossem ocupadas de forma produtiva (SILVA e SECRETO, 1999). Concebido para a realidade portuguesa, o instituto das sesmarias era voltado para terras que já haviam sido lavradas e estavam abandonadas, portanto tinha o sentido de incentivar a ocupação da terra para produção de alimento. 


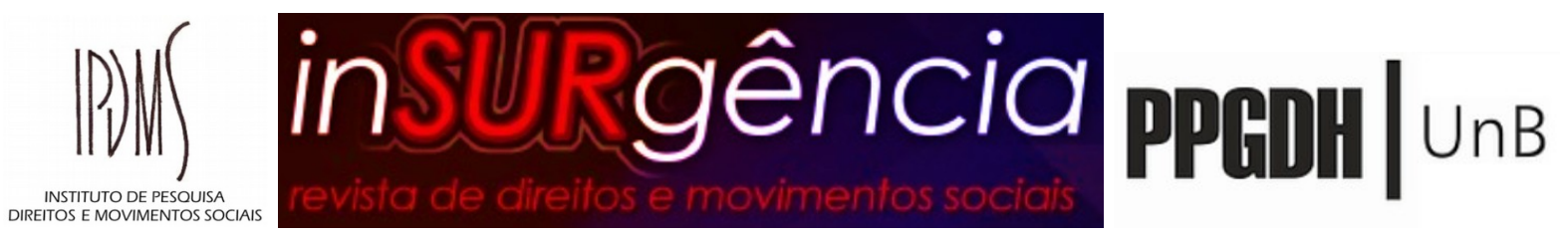

Ocorre que as terras do Brasil não estavam abandonadas, mas ocupadas pelos povos indígenas. Portanto, o intuito das sesmarias no Brasil era o de legitimar o direito de conquista de Portugal e invisibilizar os povos indígenas e o tipo de uso que davam à terra (MARÉS, 2003). Sendo assim, Marés afirma que a primeira providência legal para a aprovação da Lei de Terras de 1850 foi a conceituação jurídica de terras devolutas, que passaram a ser não as desocupadas, como se costuma referir, mas as que não eram legalmente adquiridas.

Ocupando esta categoria de terras chamadas devolutas tem-se uma diversidade de sujeitos coletivos no Brasil, entre indígenas, quilombolas, ribeirinhos, campesinos, de modo que o antropólogo Paul Little entende que a melhor forma de situar o próprio conceito de povos e comunidades tradicionais é no plano de reivindicações territoriais dos grupos sociais fundiariamente diferenciados frente ao Estado brasileiro” (LITTLE, 2002, p. 23) considerando que "têm como foco principal, o reconhecimento da legitimidade de seus regimes de propriedade comum e das leis consuetudinárias que os fundamentam” (LITTLE, 2002, p. 23). As noções de diversidade territorial e territorialidades possibilitam abarcar as formas de relação com a terra que não se encaixam na lógica proprietária.

O reconhecimento jurídico dos direitos territoriais tem asseio constitucional, desde os artigos 215 e 216, que compõem o Capítulo da Cultura da Constituição de 1988, bem como no artigo 231, que trata especificamente dos direitos dos povos indígenas, e o artigo 68 do ADCT que trata dos direitos dos povos de quilombo. Além destes, ressalte-se o Decreto Federal 6040/2007 que instituiu a Política Nacional de Desenvolvimento Sustentável dos Povos e Comunidades Tradicionais e o disposto na Convenção 169 da OIT (recebida no ordenamento nacional pelo Decreto n. 10.088/2019), especialmente, o direito de consulta prévia, livre e informada. Deste modo, sustenta-se que o ordenamento jurídico brasileiro, dado o tratamento constitucional à matéria, alçou os direitos territoriais de povos e comunidades tradicionais a categoria de direitos fundamentais, um tipo de direito humano. $\mathrm{O}$ caráter coletivo, dinâmico e plural dos direitos territoriais diferem-nos fundamentalmente do direito de propriedade, pois sua natureza jurídica é de direito público (CUNHA e SANTOS, 2020).

Nesse sentido, seria possível chamar estes territórios diversamente ocupados ao longo do Brasil, ou mesmo em Pontal do Paraná, de comuns? Na obra Comum: ensaios sobre a revolução no século XXI (2017), Pierre Dardot e Christian Laval ao proporem um genealogia do conceito de comum, esforçam-se por distingui-lo da noção de propriedade 


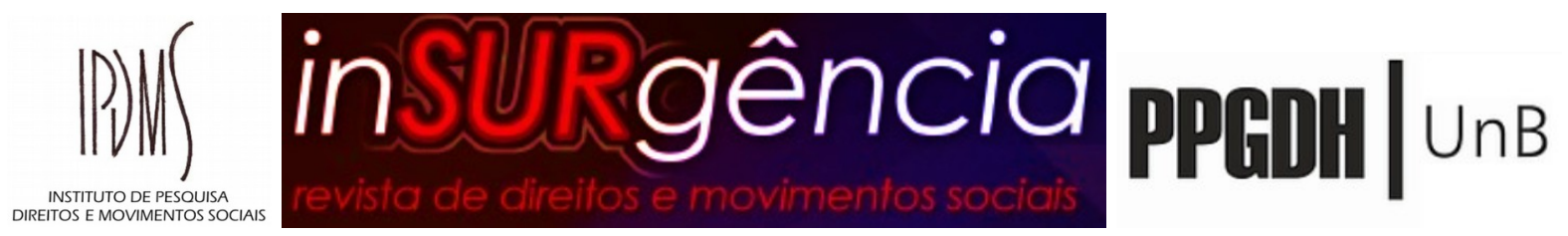

pública. Como seu objeto é a concepção de comum deste uma construção ocidental, os autores refazem o percurso do conceito desde a tradição grega. Dardot e Laval entendem que a doutrina política romana esvaziou o sentido grego do comum através da estatização e da espiritualização do comum no contexto cristão. Quanto a estatização romana do comum, esta seria a raiz da doutrina da soberania que prega que o Estado é o detentor da "vontade comum”.

Segundo os autores a propriedade pública “deixou de se mostrar como uma proteção do comum e passou a ser a forma “coletiva” de propriedade privada reservada à classe dominante, que podia dispor dela como bem entendesse e espoliar a população conforme seus desejos e interesses” (DARDOT e LAVAL, 2017, p. 15). A noção da propriedade pública ou da propriedade do Estado como uma forma de espoliação da população é muito mais evidente nos casos dos países que ocuparam o lugar de colônias na gênese do sistema-mundo capitalista, nos termos de Wallerstein. A espoliação e a despossessão dos povos originários constituiu as Américas, através da despossessão e espoliação de africanos sequestrados e escravizados.

A proposta de Dardot e Laval (2017) tem por um lado, a preocupação em combater a reificação dos comuns, entendidos ou como inapropriáveis por natureza ou exterioridades econômicas. A ideia de coisas ou bens comuns pressupõe uma relação singular entre direito e realidade, de acordo com os autores, de um naturalismo evidente, o direito "se limitaria a validar uma realidade em relação a qual ele seria impotente” (DARDOT e LAVAL, 2017, p. 15). O que ocorre de fato é que o direito através de suas categorias cria suas próprias realidades, e ao invés de tentar invisibilizar essa operação, deveria afirmá-la.

Por outro lado, os autores buscam afirmar um conceito de comum que não esteja vinculado a nenhuma essência humana, que não decorra de da ideia de humanidade como coletivo. Defendem um conceito de comum pensado como co-atividade, e não copertencimento, co-propriedade ou co-possessão. Neste sentido, “somente a atividade prática dos homens pode tornar as coisas comuns, do mesmo modo que somente essa atividade prática pode produzir um novo sujeito coletivo, em vez de afirmar que tal sujeito preexista a essa atividade na qualidade de titular de direitos” (DARDOT e LAVAL, 2017, p. 53). Pois, para os autores, o comum só pode surgir com o rompimento do confronto metafísico entre sujeito livre dominador e objeto a ser dominado. 


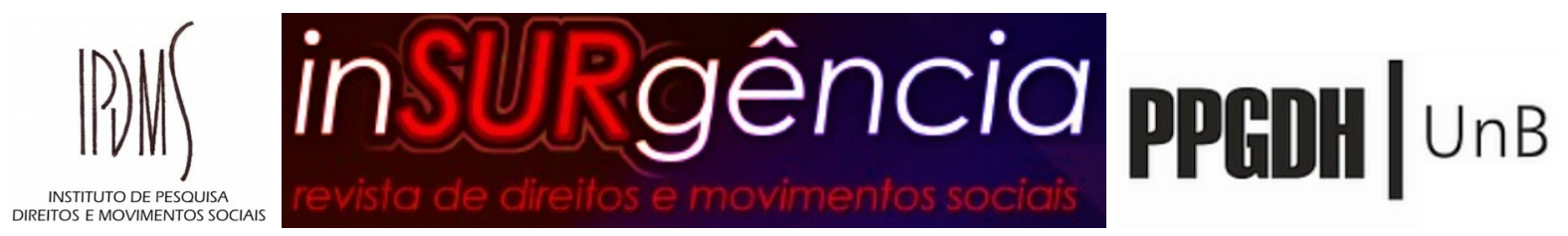

Dizer aqui que os territórios dos povos e comunidades tradicionais do Brasil, ou mesmo as terras devolutas ocupadas por pequenas comunidades, constituem comuns seria enquadrá-los numa categoria que talvez nem lhes convenha. Porém, se percebe que o conceito vem adentrando os discursos dos movimentos sociais de luta pela terra e o território, especialmente os protagonizados pelos povos e comunidades tradicionais. Os comuns encontram ressonâncias com a noção de bem-viver, alternativa ao modelo capitalista desenvolvimentista proposta desde os paradigmas dos povos originários da Bolívia, Equador, Peru e Colômbia. Aparecem a partir do que Maristela Svampa nominou "giro ecoterritorial das lutas” (SVAMPA, 2016), a confluência entre a matriz indígena-comunitária e o ambientalismo. O conceito de comuns ou bens comuns, no âmbito dos movimentos socioambientais, integra diversas percepções que defendem a necessidade de se manter fora do mercado "recursos naturais” cujo valor transcende qualquer tentativa de monetarização.

\section{Considerações finais}

Este artigo se propôs a narrar a história da apropriação privada de terras devolutas de uma pequena cidade no litoral do Paraná, de modo a denunciar a série de ilegalidades perpetuadas nesse processo, não por partir do pressuposto de que se trata de uma anomalia jurídica, mas exatamente por entender que tais ilegalidades são constitutivas da história fundiária do Brasil.

A pretensão de industrializar e criar um porto em Pontal do Paraná dependia da revogação e alteração de normas jurídicas de ordenamento territorial para que ganhasse a legitimidade jurídica necessária para se impor como imperativo de desenvolvimento, conforme contamos de forma breve. Essa operação com o direito foi da ordem de moldar a norma aos empreendimentos, quando na verdade, seriam os empreendimentos que teriam que se moldar a norma.

O direito não se identifica diretamente com a norma, entretanto tem na norma uma de suas expressões mais contundentes. Sobretudo, o direito é fonte de legitimação pois é “instituição, no sentido mais profundo do termo” (OST, 1995, p. 21). Sendo assim, podemos afirmar que o direito institui como verdade ficções operatórias que traduzem um sentido coletivamente decidido. Dito de outro modo, o direito é a instituição mais profunda porque institui todas as outras, o fundamento desse poder do direito numa leitura contemporânea é a 


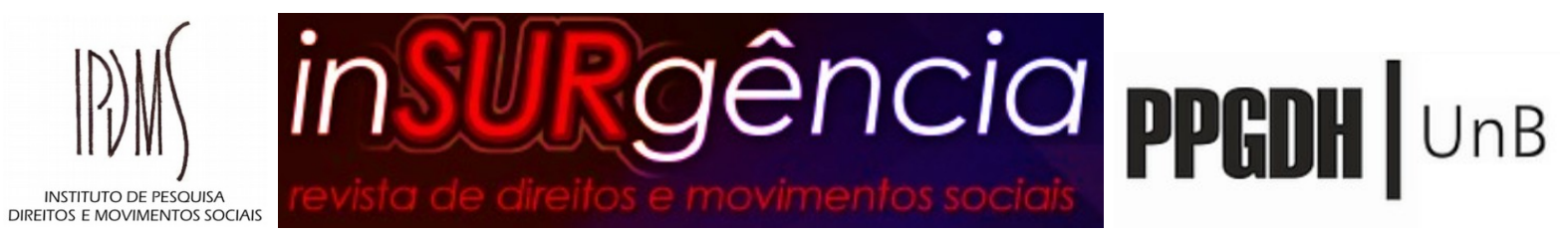

sua “democraticidade”, “a centralidade da soberania da constituição é a centralidade da soberania do povo” (HESPANHA, 2006, p. 354). Outrossim, o foco posto aqui não é o fundamento do direito mesmo, mas o fundamento da norma, que está no direito. O direito funda a norma e não o contrário, portanto conforme a lógica jurídica, uma nova norma tem que se adequar ao sistema de normas previamente existente a ela.

Essa operação de mudar a norma para atender a interesses de grupos específicos que visam produzir transformações profundas na dinâmica de uma cidade promovendo sua industrialização através da instalação de um megaempreendimento portuário nos serve de mapa para propor uma reflexão a respeito da perversão de instrumentos jurídicos para atender a interesses específicos. Tal não é uma denúncia nova e já foi bem explorada pela teoria crítica do direito, porém, aqui buscamos situá-la no território explorando conexões do conceito de comuns e da diversidade territorial brasileira, desde uma breve análise histórica da política fundiária.

Entre latifúndios e latifundiários há uma enorme variedade de povos e comunidades tradicionais que constituem a diversidade territorial do país, resistindo às pressões do modelo hegemônico e reinventando-se através da incorporação da ecologia nas lutas por seus direitos territoriais. Seja no campo, seja nas cidades, pois esta diversidade territorial também ultrapassa este dualismo ocidental. Trazemos, assim, o conceito de comuns como uma ferramenta contestatória e uma chave conceitual para propor alternativas analíticas e reivindicatórias de direitos que se adequem a diversidade territorial brasileira.

\section{Referências}

ACSERALD, Henri. O zoneamento ecológico-econômico e a multiplicidade de ordens socioambientais na Amazônia. In: Novos cadernos, v. 3, n. 2, p. 5-15. Belém: UFPA, 2000.

ARANTES, Otília Beatriz Fiori. Uma estratégia fatal: a cultura nas novas gestões urbanas. In: A cidade do pensamento único: desmanchando consensos. Otília Arantes, Carlos Vainer, Ermínia Maricato (Orgs). Petrópolis: Vozes, 2013.

CUNHA, Isabella Madruga da. Cidade, Lei e Desenvolvimento: Pontal do Paraná, uma estrada para o futuro? Dissertação (Mestrado em Meio Ambiente e Desenvolvimento.Curitiba: UFPR, $2018 . \quad$ Disponível em: $<$ https://acervodigital.ufpr.br/handle/1884/58910>, último acesso em 27 de julho de 2020.

CUNHA, Isabella Madruga da. SANTOS, Thais Giselle Diniz dos. Direitos Territoriais no Brasil: Análise interdisciplinar de uma categoria jurídica autônoma. In: Revista Culturas Jurídicas, Ahead of Print, Vol. 7, Núm. 17, mai./ago., 2020. 


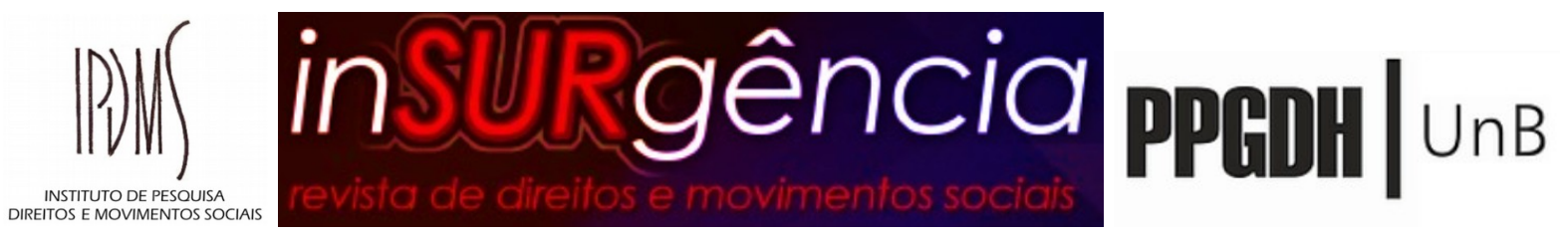

DARDOT, Pierre; LAVAL, Cristian. Comum: ensaio sobre a revolução no século XXI. Tradução de Mariana Echalar. São Paulo: Boitempo Editora, 2017.

HESPANHA, António Manuel. O caleidoscópio do direito: o direito e a justiça nos dias e no mundo de hoje. Coimbra: Almedina, 2009.

LITTLE, Paul E. Territórios sociais e povos tradicionais no brasil: por uma antropologia da territorialidade. Brasilía: UNB, 2002.

MARÉS, Carlos Frederico. A função social da terra. Porto Alegre: Sergio Antonio Fabris, 2003.

MARICATO, Erminia. O impasse da política urbana no Brasil. Petrópolis: Vozes, 2014.

MARICATO, Erminia. Brasil, cidades: alternativas para a crise urbana. Petrópolis: Vozes, 2013a.

MARICATO, Erminia. As ideias fora do lugar e o lugar fora das ideias: planejamento urbano no Brasil. In: A cidade do pensamento único: desmanchando consensos. Otília Arantes, Carlos Vainer, Ermínia Maricato (Orgs). Petrópolis: Vozes, 2013 b.

OST, François. A natureza à margem da lei: ecologia à prova do direito. Lisboa: Instituto Piaget, 1995.

PIERRI, Naina. O litoral do Paraná: entre a riqueza natural e a pobreza social. In: Desenvolvimento e Meio Ambiente, n. 8, p. 25-41. Curitiba: UFPR, 2003.

PRIORI, Angelo. Legislação e política fundiária no Estado do Paraná (1889-1945). In: Sæculum: Revista de história, v. 26. jan./jun, 2012. João Pessoa: UFPB, 2012.

SAMPAIO, Roberto. Ocupação das orlas das praias paranaenses pelo uso balneário. In: Desenvolvimento e Meio Ambiente, n. 13, p. 169-186, jan./jun, 2006. Curitiba: UFPR, 2006a

SERRA, Elpídio. Extremo noroeste do Paraná: dos conflitos pela posse da terra aos conflitos pela reforma agrária. In: Anais do X Encontro de Geógrafos da América Latina. São Paulo: USP, 2005.

SILVA, Ligia Maria Osório. SECRETO, María Veronica. Terras públicas, ocupação privada: Elementos para a história comparada da apropriação territorial na Argentina e no Brasil. In: Economia e Sociedade, (12): 109-41, jun. 1999. Campinas: UNICAMP, 1999.

SILVA, Luiz Geraldo Santos da. Caiçaras e Jangadeiros: Cultura marítima e modernização no Brasil. Coord. Antonio Carlos Diegues. São Paulo: CEMAR/USP, 1993.

SVAMPA, Maristela. Extrativismo neodesenvolvimentista e movimentos sociais: um giro ecoterritorial rumo a novas alternativas? In: Descolonizar o imaginário: debates sobre o pós-extrativismo e alternativas ao desenvolvimento. Gerhard Dilger, Miriam Lang, Jorge Pereira Filho (Orgs). São Paulo: Fundação Rosa Luxemburgo, 2016

Submetido em 18/06/2020.

Aprovado em 21/07/2020. 